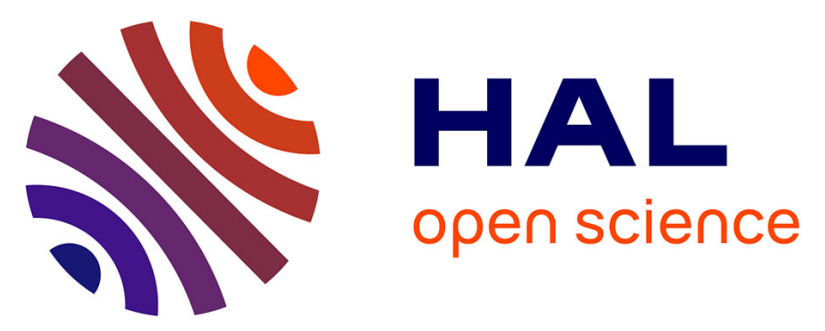

\title{
Atomic structure of the nanocrystalline Si particles appearing in nanostructured Si thin films produced in low-temperature radiofrequency plasmas
}

Gregorio Viera, Maxime Mikikian, Enric Bertran, Pere Roca I Cabarrocas, Laifa Boufendi

\section{To cite this version:}

Gregorio Viera, Maxime Mikikian, Enric Bertran, Pere Roca I Cabarrocas, Laifa Boufendi. Atomic structure of the nanocrystalline Si particles appearing in nanostructured Si thin films produced in low-temperature radiofrequency plasmas. Journal of Applied Physics, 2002, 92 (8), pp.4684. 10.1063/1.1506382 . hal-00432375

\section{HAL Id: hal-00432375 https://hal.science/hal-00432375}

Submitted on 16 Nov 2009

HAL is a multi-disciplinary open access archive for the deposit and dissemination of scientific research documents, whether they are published or not. The documents may come from teaching and research institutions in France or abroad, or from public or private research centers.
L'archive ouverte pluridisciplinaire HAL, est destinée au dépôt et à la diffusion de documents scientifiques de niveau recherche, publiés ou non, émanant des établissements d'enseignement et de recherche français ou étrangers, des laboratoires publics ou privés. 


\title{
Atomic structure of the nanocrystalline Si particles appearing in nanostructured Si thin films produced in low-temperature radiofrequency plasmas
}

\author{
G. Viera ${ }^{1}$, M. Mikikian ${ }^{1}$, E. Bertran ${ }^{2}$, P. Roca i Cabarrocas ${ }^{3}$ and L. Boufendi ${ }^{1 *}$ \\ ${ }^{1}$ Groupe de Recherche sur l’Energétique des Milieux Ionisés (GREMI), BP 6744, \\ Université d’Orléans, 45067 Orléans, Cedex 02, France \\ ${ }^{2}$ FEMAN, Dep. Física Aplicada i Òptica, Universitat de Barcelona. Avgda. Diagonal, 647, E08028 Barcelona, \\ Spain. \\ ${ }^{3}$ Laboratoire de Physique des Interfaces et des Couches Minces. (CNRS, UMR7647), \\ Ecole Polytechnique, 91128 Palaiseau, Cedex France
}

\begin{abstract}
Nanostructured Si thin films, also referred as polymorphous, were grown by plasma-enhanced chemical vapor deposition. The term "polymorphous" is used to define silicon material that consists of a two-phase mixture of amorphous and ordered Si. The plasma conditions were set to obtain $\mathrm{Si}$ thin films from the simultaneous deposition of radical and ordered nanoparticles. Here, a careful analysis by electron transmission microscopy and electron diffraction is reported with the aim to clarify the specific atomic structure of the nanocrystalline particles embedded in the films. Whatever the plasma conditions, the electron diffraction images always revealed the existence of a well-defined crystalline structure different to the diamondlike structure of Si. The formation of nanocrystallinelike films at low temperature is discussed. A Si face-cubic-centered structure is demonstrated here in nanocrystalline particles produced in low-pressure silane plasma at room temperature.
\end{abstract}

\section{INTRODUCTION}

The generation of powder in silane-based radiofrequency (rf) low-pressure plasmas has attracted a great interest in the last decade [1-4]. The initial studies were driven by the contamination effects of powder during the preparation of amorphous silicon ( $a$-Si:H) thin films by plasma enhanced chemical vapor deposition (PECVD). It is widely recognized that the formation of powder in PECVD is originated by gas-phase polymerization reactions [5-7]. The long residence time of the powder particles in the plasma, electrically confined by the plasma sheaths, favors their further growth first by agglomeration of small particles and then by deposition of neutral and ion radicals on their surface [8-10]. The formation of powder is known to be reduced by decreasing either the reactive gas pressure or the electrical power supplied to the discharge, or by increasing the substrate temperature. However, this often leads to a limitation of the film deposition rate, which is contrary to the industrial requirements of making silicon-based devices with high deposition rate and film qualities.

The square wave modulation (SQWM) of the rf power amplitude applied to the plasma has been revealed as a suitable method for inhibiting powder formation [5, 11-13]. Plasma modulation consists of alternating periods of plasma-on time $\left(\mathrm{T}_{\text {on }}\right)$ with afterglow periods $\left(\mathrm{T}_{\text {off }}\right.$ ). For any given set of plasma conditions, it is possible to find a plasma modulation that inhibits the appearance of powder particles: $T_{\text {on }}$ is set short enough so that no particles are formed, and $\mathrm{T}_{\text {off }}$ is chosen long enough to completely extinct the anion population in order to avoid their further polymerization in the next $\mathrm{T}_{\text {on }}$. Therefore, modulated discharges allow to use high rf powers and moderate substrate temperatures while avoiding the formation of powder particles.

Recently, however, silicon thin films grown with a significant contribution of nanoparticles coming from the plasma have been found to exhibit improved properties of transport and stability and high optical gap as compared to $a$-Si:H [14-17]. The knowledge of the powder formation pathway and the use of modulated rf plasma have permitted anew the selective incorporation of nanocrystallites of few nanometers into the growing thin film $[18,19]$. These films have been described as a mixture of amorphous and ordered material and called as polymorphous $\mathrm{Si}$ (pm-Si:H) [1416] or as nanostructured $\mathrm{Si}$ (ns-Si:H) [20-22]. It has been claimed than the unusual structure of these films, dominated by the ordered structure of the $\mathrm{Si}$ nanoparticles embedded therein, is the responsible for the unusual properties of pm-Si:H. However, there is no clear picture on the atomic structure of these $\mathrm{Si}$ nanoparticles or clusters of $\sim 2 \mathrm{~nm}$. This question will

\footnotetext{
*Corresponding Author: laifa.boufendi@univ-orleans.fr
} 
TABLE I. Samples of nanostructured films and free-standing nanoparticles of Si obtained using different plasma conditions and different plasma reactors.

\begin{tabular}{|c|c|c|c|c|c|c|c|c|}
\hline Sample & {$\left[\mathrm{SiH}_{4}\right](\mathrm{sccm})$} & [inert gas] (sccm) & $\mathrm{T}\left({ }^{\circ} \mathrm{C}\right)$ & $\mathrm{p}(\mathrm{Pa})$ & $\mathbf{P}_{\mathrm{INC}}\left(\mathrm{mW} / \mathrm{cm}^{2}\right)$ & $T_{\text {on }}(s)$ & $T_{\text {off }}(s)$ & $\mathrm{n}^{0}$ cycles \\
\hline $\mathrm{ns}-\mathrm{Si}(\mathrm{A})^{\mathrm{a}}$ & 1 & $30 \mathrm{sccm} \mathrm{H} \mathrm{H}_{2}$ & 100 & 6 & 10 & \multicolumn{3}{|c|}{$\mathrm{CW}$} \\
\hline $\mathrm{ns}^{\mathrm{n}-\mathrm{Si}(\mathrm{B})^{\mathrm{a}}}$ & \multicolumn{2}{|c|}{$2 \% \mathrm{SiH}_{4}$ in $\mathrm{H}_{2}$} & 200 & 160 & 110 & \multicolumn{3}{|c|}{ CW } \\
\hline$\overline{\text { ns-Si (C) }}{ }^{\mathrm{b}}$ & 1.2 & $\begin{array}{ll}30 \mathrm{sccm} \mathrm{Ar} \\
\end{array}$ & 25-150 & 12 & (260 & $0.1-5$ & 19 & - \\
\hline ns-Si (D) ${ }^{\mathrm{a}}$ & 1 & $30 \mathrm{sccm} \mathrm{Ar}$ & RT & 20 & 175 & 1 & 19 & 10 \\
\hline$\overline{\mathrm{ns}-\mathrm{Si}(\mathrm{E})^{\mathrm{c}}}$ & 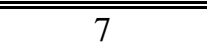 & $133 \mathrm{sccm} \mathrm{Ar}$ & $\overline{\overline{\mathrm{RT}}}$ & 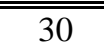 & $\overline{\overline{500}}$ & 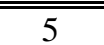 & 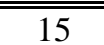 & $\overline{10}$ \\
\hline
\end{tabular}

${ }^{\mathrm{a}}$ Thin films and nanoparticles obtained in the laboratory Laboratoire de Physique des Interfaces et des Couches Minces, Ecole Polytechnique, Palaiseau ( France)

b Thin films deposited in the laboratory Groupe de Recherches sur l'Energétique des Milieux Ionisés (GREMI), Université d’Orléans, Orléans (France)

${ }^{c}$ Nanoparticles obtained in the laboratory Grup de Fisica i Enginyeria de materials amorf i nanostructurats (FEMAN), Dep. Fisica Aplicada i Optica, Universitat de Barcelona (Spain)

be discussed in this paper from results of highresolution transmission electron microscopy (HRTEM) and selected area electron diffraction (SAED).

In the following, an overview of the atomic structure of Si both in the amorphous and crystalline phase is presented.

The atomic structure of microcrystalline $\mathrm{Si}(\mu \mathrm{c}-\mathrm{Si})$ consists of $\mathrm{Si}$ ordered domains with the diamond crystal structure. The diamond lattice is formed by two interpenetrating face-centered cubic (fcc) lattices, displaced along the body diagonal of the cubic cell by $1 / 4$ the diagonal length. Each Si atom is surrounded by four near neighbors forming a tetrahedron (the coordination number is 4). The unit cell contains 8 atoms and the lattice constant $a$ is $5.4282 \AA$. The diamond structure is the less dense of the different phases that Si can attain when subjected to compression.

For crystalline domains of a fraction of a micron, the films are referred to as polycrystalline $\mathrm{Si}$ (pc-Si). In previous works, Veprek et al. [23] reported on diamond-structured nanocrystals formed in different chemistries and claimed that $3 \mathrm{~nm}$ represents the limit size for their stability. By taking into account that the number density of Si atoms in the diamond lattice is $5 \cdot 10^{28} \mathrm{at} \cdot \mathrm{m}^{-3}$ (calculated from the quotient between the number of atoms of the unit cell and its volume) and by considering Si spheres of $30 \AA$, the total number of atoms is around 700. This is therefore the minimum number of atoms necessary to form a Si diamondlike crystal thermodynamically stable. However, as we will discuss in this article, Si crystallites smaller that $3 \mathrm{~nm}$ but with atomic structures different from the diamond lattice, have been experimentally observed [20].

The amorphous structure of $\mathrm{Si}$ is described as a disordered lattice of atoms, bonded with tetrahedral coordination, and with a small distortion both in bond length and angle when compared to diamond crystalline $\mathrm{Si}$. The short-range order reaches only the first and second neighbors. The distance to first neighbors is the same as in crystalline $\mathrm{Si}$ and equal to $2.35 \AA$ (with a distortion of 1-3\%), and the distance to second neighbors is $3.5 \AA$ (with a distortion larger than $10 \%$ ).

Ordered domains of $\mathrm{Si}$ of a few nanometers are normally referred as Si clusters, rather than as small crystallites. Although it is recognized that the most stable structure of small Si clusters of some ten of atoms is not the diamond structure [24], there is no general agreement on the structure of the $\mathrm{Si}$ nanocrystallites which are only a few nanometers in size. Different kind of structures can be found in the literature, such as cagecore or clathrate structures [25-29].

This paper will highlight that the $\mathrm{Si}$ ordered structures of 1-5 nm formed in $\mathrm{SiH}_{4}$-based rf plasmas present an atomic structure with well-defined crystalline geometry different from those known for $\mathrm{Si}$ clusters and for stable bulk Si.

\section{EXPERIMENT}

\section{A. Sample preparation}

For the synthesis of nanoparticles containing $\mathrm{Si}$ thin films by PECVD, the range of plasma conditions should be different from those usually adopted for $a$ $\mathrm{Si}: \mathrm{H}$ thin film deposition. These films can be obtained using a wide range of plasma conditions (temperature, rf (13.56 MHz) power and modulation, gas pressure and $\mathrm{SiH}_{4}$ gas dilution) but always close to the formation of powder in order to allow the formation of Si nanoparticles in the discharge. In this study, samples obtained in different plasma reactors and using different plasma conditions have been considered. This allows to avoid any spurious effect coming from a particular plasma reactor setup. In addition, the structure of nanoparticles embedded in the matrix of thin films or deposited directly on a suitable TEM grid will be analyzed. Therefore, the nanoparticle/matrix interface will be taken into account. In the following, the different plasma conditions are presented and summarized in Table I. From here, we will use the term nanostructured Si (ns$\mathrm{Si}$ ) to group all nanoparticle-containing thin films. 
ns-Si(A): pm-Si:H thin films from continuous-wave (cw) rf plasmas under conditions of very low particle development (low deposition temperature, high $\mathrm{H}_{2}$ dilution, low pressure and low rf power) [20-21]. The plasma reactor is a grounded cylindrical box, with two parallel electrodes of $15 \mathrm{~cm}$ diameter, $2.8 \mathrm{~cm}$ apart [30]. The gas mixture is injected from the back of the rf electrode (cathode), confined by the plasma box, and it is flowed out through the edges of the sample plate located on the grounded electrode (anode). The process temperature is related to the substrate temperature.

The process parameters were optimized to be just before the onset of the formation of powder, thus allowing the formation of Si nanoparticles of 1-3 nm in the plasma but not larger powder particles [18]. These nanoparticles are not electrostatically confined by the plasma sheaths, they can leave the plasma and thus contribute to film growth in a cw discharges.

ns-Si(B): pm-Si:H thin films from cw rf plasmas, high deposition temperature, high $\mathrm{H}_{2}$ dilution, high pressure and high rf power [31]. The plasma setup was the same than for the sample ns-Si(A).

ns-Si(C):pm-Si:H thin films from square-wave modulated (SQWM) rf plasmas using different plasma-on time, different gas temperature, high Ar dilution, low pressure and moderate rf power [19]. The plasma reactor is a grounded cylindrical box, with two parallel electrodes of $13 \mathrm{~cm}$ diameter, $3.5 \mathrm{~cm}$ apart [32]. The gas mixture is shower-like injected, using a showerhead cathode and it is flowed out through the bottom of the box that is closed with a $20 \%$ transparency grid. Samples are located on the anode. Plasma box is surrounded by a cylindrical oven that allows the gas temperature to be varied from room temperature to $200^{\circ} \mathrm{C}$. The gas temperature is measured in the gas flow below the bottom grid by means of a J-type thermocouple.

The Si films were deposited in dusty plasma conditions, i.e., in the presence of powder particles in the plasma gas phase. Plasma modulation and gas temperature were changed to control powder development pathway. These experimental conditions were adapted from previous particle generation studies done by laser light scattering (LLS) and laser induced particle explosive evaporation (LIPEE) [5, 32].

ns-Si(D): Free-standing nanocrystalline Si particles from SQWM rf plasmas, room temperature, high Ar dilution, moderate pressure and high rf power [18, 22]. The plasma reactor setup is similar to that described for ns-Si(A), but the parallel electrodes were $12 \mathrm{~cm}$ diameter, $3.7 \mathrm{~cm}$ apart.

The plasma conditions were adapted from the studies referenced for the ns-Si(C) sample and from ex-situ TEM studies [18]. For TEM analysis, particles were directly collected using suitable grids placed on the base of plasma box, onto which powder particles fell down during the plasma-off periods. The process was maintained for a few number of modulation cycles. This limits both the formation of an excessive amount of particles and the deposition of a thin film that would make the characterization of the particles difficult.

ns-Si(E): Free-standing nanocrystalline Si particles using similar plasma conditions than for ns-Si (D), but with different reactor geometry [33]. The plasma reactor is a grounded square box, with two parallel electrodes of $20 \mathrm{~cm}$ diameter, $9 \mathrm{~cm}$ apart. The gas mixture is injected through an edge of the anode, flows parallel to the electrodes and is evacuated through an outlet seam located on the opposite edge of the anode. This configuration allows a laminar flow to be piped on the samples. The process temperature is related to the substrate temperature.

The plasma parameters have been adapted, for particle formation in Ar-diluted $\mathrm{SiH}_{4}$ plasmas, on the basis of previous ex-situ TEM studies on particle growth in pure $\mathrm{SiH}_{4}$ rf discharges in order to attain similar particle population in both cases.

\section{B. Sample characterization}

HRTEM and TEM images as well as SAED patterns were obtained with a Philips CM30 microscope working at $300 \mathrm{kV}$. When nanoparticles were analyzed, the TEM grids used to collect them inside the plasma reactor had a holey membrane (allowing HRTEM and SAED images to be done) which was covered by a thin carbon layer to avoid particles charging during electron beam irradiation. When thin films were analyzed, an ex-situ sample preparation was required. The samples were prepared for cross-section observation using the conventional thinning method: first they are mechanically polished using abrasive materials and finally thinned with ion milling. The magnification of the HRTEM images, used to calculate structural characteristics of the films, was verified from measurements on the $c$-Si substrate oriented along $<110>$ by knowing that the interplanar distance of the $\{111\}$ faces is $3.14 \AA$.

\section{RESULTS AND DISCUSSION}

\section{A. Conventional TEM analysis}

Figure 1 shows TEM and SAED micrographs of the ns-Si(A) sample. The interface with the substrate corresponds to an $a$-Si:H layer of $0.8 \mu \mathrm{m}$ thick (layer A). The following layers (layer B and C) result from the incorporation of small $\mathrm{Si}$ nanoparticles of few nanometers which can contribute to film deposition during cw rf discharges. These nanoparticles represent the first population of particles appearing in the plasma gas-phase before the onset of coagulation [8$10]$. Due to their very small size $(1-2 \mathrm{~nm})$ they experience charge fluctuations and consequently when a neutral (or positive) state occurs they are not 

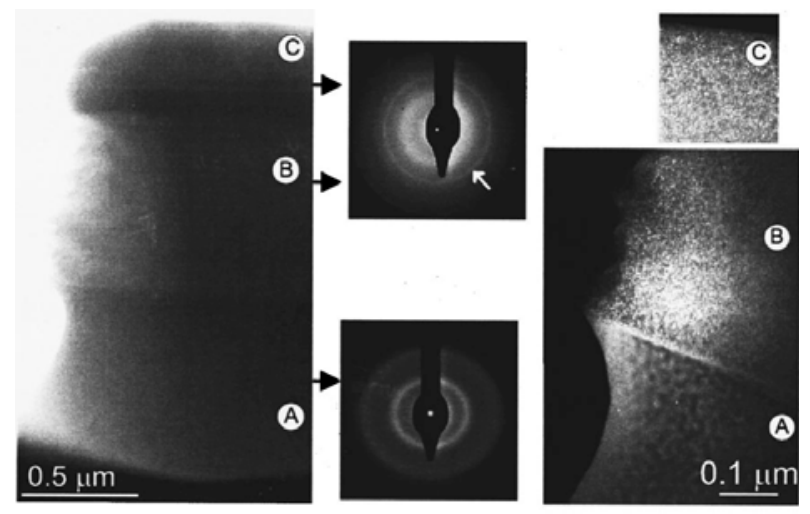

FIG. 1. Cross-sectional bright field TEM images (left), SAED patterns (center), and the corresponding dark-field images (right) of a ns-Si(A). The first layer over the substrate (A) corresponds to an amorphous Si thin film. The layers (B) and (C) were grown by the simultaneous deposition of Si radicals and nanoparticles (conditions reported in Sec. A of the experimental part). In the SAED image of layers (B) and (C), a sharp diffraction ring is pointed out by an arrow.

electrostatically confined by the plasma sheaths [34]. At this stage they can leave the plasma and contribute to film deposition. Dark field and SAED images were taken for each individual layer (central and right images in Fig. 1). The SAED of the first layer contains the diffuse rings characteristics of amorphous Si. The corresponding dark field image appears uniformly lighted, thus confirming the amorphous character of the layer. However, for the subsequent layers, a careful inspection of the corresponding SAED images revealed the existence of sharp rings (the most intense ring is pointed out by an arrow in the figure) superimposed on diffused rings, thus indicating the presence of ordered structures in an amorphous matrix. As it will be discussed in Sec. 3C, such SAED pattern is different from that of the diamondlike structure of crystalline Si. The dark-field images of the layers (B) and (C) clearly reveal the presence of nanocrystalline regions, corresponding to the specular reflections in dark field. Direct measurements on high-resolution TEM micrographs, not shown here, indicate a crystallite size of about 1-2 nm. In order to determine the size of the crystallites from the dark field images, we have used image processing and analysis software to identify the bright points and to extract their features (quantity, area, perimeter, roundness, etc). By means of this software, the size histograms were determined [19].

Figure 2 shows another example of nanostructured Si thin film but with a higher concentration of ordered domains, which is evident from its dark field and SAED images. This film corresponds to a ns-Si(C) sample using $\mathrm{T}_{\mathrm{ON}}=5 \mathrm{~s}$ and $\mathrm{T}_{\mathrm{G}}=100^{\circ} \mathrm{C}$. The plasma conditions used here were chosen to attain powder formation contrary to the previous case (ns:Si(A) film
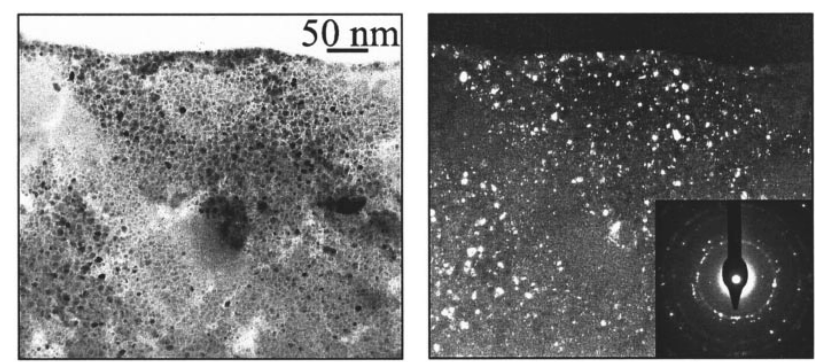

FIG. 2. Bright field (left) and dark-field (right) TEM images of a nanostructured Si thin film deposited from modulated rf plasmas of Ar-diluted $\mathrm{SiH}_{4}$ in dust-forming conditions (ns-Si(C), with $\mathrm{T}_{\mathrm{ON}}=5 \mathrm{~s}$ and $\mathrm{T}_{\mathrm{G}}=100{ }^{\circ} \mathrm{C}$ ). The insert in the dark-field image shows the corresponding SAED pattern.

shown in Fig. 1). The selective incorporation of nanoparticles into the growing film was controlled through the square-wave modulation of the rf plasma [19]. During the plasma-on time $\left(\mathrm{T}_{\mathrm{on}}\right)$ of the modulation cycle, an amorphous Si film is deposited onto the substrate and, at the same time, nanoparticles nucleate and grow in the plasma gas phase. During the afterglow periods $\left(\mathrm{T}_{\text {off }}\right)$, the particles leave the plasma and are deposited onto the amorphous Si film. Consequently, after a great number of cycles, the final structure will consist of Si nanoparticles embedded in an amorphous matrix. In particular, the $\mathrm{T}_{\text {on }}$ used to grow the ns-Si (C) sample shown here is slightly larger than the characteristic time for particle coagulation, thus explaining the presence of larger crystallites in the film as observed in Fig. 2 [8,10,19].

Of great relevance is that the ns-Si(C) sample shown in Fig. 2 presents the same distribution of sharp rings in the SAED pattern as the ns-Si(A) film analyzed in Fig. 1, in spite of the very different plasma conditions and reactor geometry. As it will be carefully discussed in the Sec. 3C, the indexation of these electron diffraction patterns highlights a fcc cell. A similar crystalline structure was found in freestanding $\mathrm{Si}$ nanoparticles formed in modulated $\mathrm{SiH}_{4}-$ Ar rf plasmas [22].

Figure 3 shows a bright field image and a SAED pattern of nanocrystalline Si particles (corresponding to the ns-Si(E) sample) deposited directly on a TEM grid (black points in the TEM figure). These particles are spherical, appear isolated and monodispersed in the TEM grid and have a radius about $5 \mathrm{~nm}$. They have a medium-range ordered structure, as revealed by the SAED image. The indexation of this pattern anew reveals the existence of a fcc structure. This result is very important, because it proves that the $\mathrm{Si}$ nanoparticles maintain the same atomic arrangement once incorporated in the film.

The questions which arise now are, i) why the $\mathrm{Si}$ nanoparticles formed under such plasma conditions appear as crystallites?; ii) how to explain the formation 


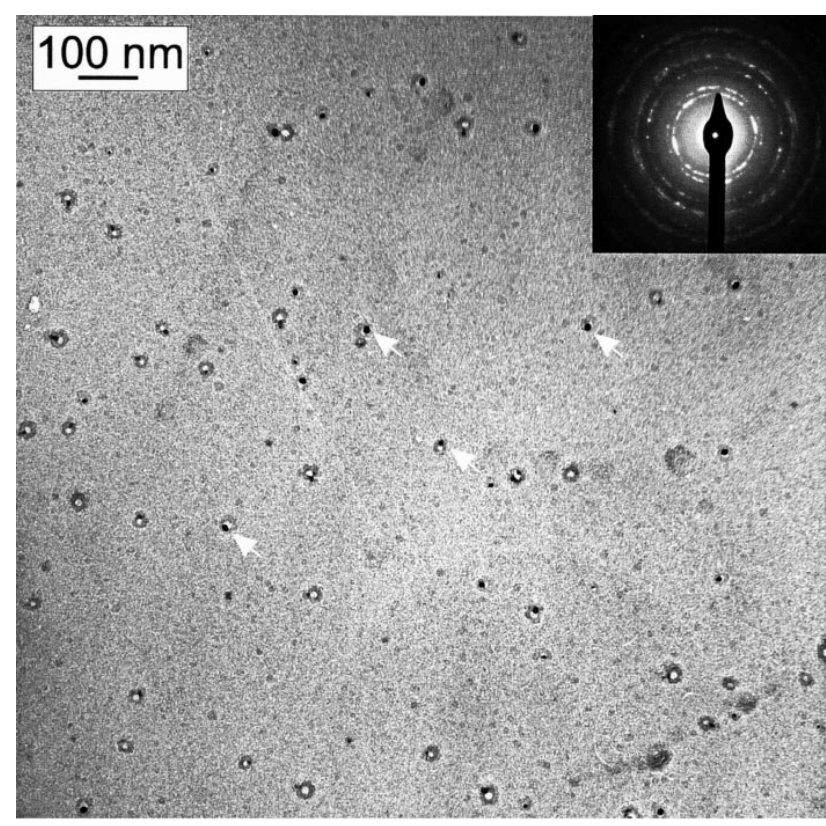

FIG. 3. Bright field TEM image of Si nanoparticles of 10 $\mathrm{nm}$ (black points in the image) obtained from modulated $\mathrm{rf}$ plasmas of Ar-diluted $\mathrm{SiH}_{4}$ (ns-Si(E)). The insert shows the corresponding SAED. The background image corresponds to a thin carbon layer covering the membrane of the TEM grid.

of a fcc crystalline structure; iii) why this structure has not been previously detected in these kinds of $\mathrm{Si}$ nanoparticles?.

The reason why such particles are crystallites is not straightforward. The formation of powder particles in rf plasmas of Ar-diluted $\mathrm{SiH}_{4}$ is known to be governed by the discharge conditions and the plasma-on duration [8-10]. Particle development can be divided into three phases: nucleation, coagulation and powder growth by molecular sticking. During the nucleation phase (particles 1-2 $\mathrm{nm}$ in size), particles with an ordered atomic structure can be formed. The coagulation of such nanocrystallites (second stage) gives rise to larger particles. Indeed, the presence of small ordered domains of a few nanometers embedded in bigger powder particles has been reported since the studies on particle formation on Ar-diluted $\mathrm{SiH}_{4}$ discharges [9].

The appearance and development of the first particles occurring in rf plasmas have been studied "in-situ" by mass spectrometry. These studies emphasized an evolution of the particle structure during its initial growth stage [35, 36]. The results indicated that these particles could not be understood as silicon cores covered by hydrogen, but as crosslinked structures. This cross-linking was found to increase with the residence-time of the particles inside the plasma. Two different physical mechanisms could explain this evolution: a) the energy supplied by ion and electron bombardment, which is enhanced in Ardiluted silane plasmas; and b) the temperature spike resulting from the collision of two smaller particles.

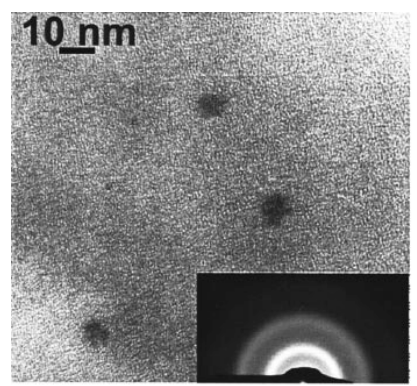

(a)

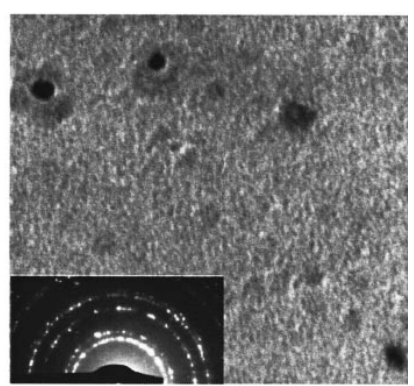

(b)
FIG. 4. TEM images of Si nanoparticles obtained (a) from pure $\mathrm{SiH}_{4}$ discharges, during 2 modulation cycles of $\mathrm{T}_{\text {on }}=$ $0.05 \mathrm{~s}$ and (b) from high Ar diluted $\mathrm{SiH}_{4}$ discharges, during 10 cycles of $\mathrm{T}_{\text {on }}=5 \mathrm{~s}$. Inserts are the corresponding SAED patterns.

This is due to the need to accommodate the excess of surface energy into the bulk. The temperature reached during coagulation is known to decrease as the particle size increases, and this agrees with the fact that only small particles appear as crystallites.

The effect of the inert-gas dilution on particle structure can be analyzed by comparing the particles formed in pure $\mathrm{SiH}_{4}$ and in Ar-diluted $\mathrm{SiH}_{4}$ rf plasmas. The plasma conditions were adjusted to have particles coming from the same development stage [33]. As compared to the case of Ar-diluted discharges, particles growing in pure $\mathrm{SiH}_{4}$ discharges have higher nucleation rate and faster kinetics of particle development. Therefore, to obtain similar particle size and particle distribution in both discharges, the processing time and the plasma-on time must be reduced in the pure $\mathrm{SiH}_{4}$ discharges. Figure 4 compares TEM micrographs of $\mathrm{Si}$ nanoparticles generated in pure $\mathrm{SiH}_{4}$ (a) and in Ar-diluted $\mathrm{SiH}_{4}$ (b) using the same plasma conditions but different processing time and $\mathrm{T}_{\text {on }}$ : (a) pure $\mathrm{SiH}_{4}(12 \mathrm{sccm})$ during 2 cycles with $\mathrm{T}_{\text {on }}=0.05 \mathrm{~s}$, and (b) $5 \% \mathrm{SiH}_{4}$ diluted in Ar (total flow of $140 \mathrm{sccm}$ ) during 10 cycles with $\mathrm{T}_{\mathrm{on}}=5 \mathrm{~s}$. Both kinds of particles are spherical, appear isolated and monodispersed in the TEM grid and have a radius about $5 \mathrm{~nm}$. However, the SAED patterns (insets in Figs. 4a and 4b) reveal important structural differences between both samples. The SAED pattern of the Si nanoparticles grown in pure $\mathrm{SiH}_{4}$ shows diffuse rings that must be assigned to an amorphous structure. However, the nanoparticles obtained in Ar-diluted plasmas exhibit the fcc ordered structure reported before. This result is very important because it emphasizes the role of the Ar dilution on the particle structure as a result of collisions of high energetic plasma species with the particles, which is clearly absent when nanoparticles are grown from pure $\mathrm{SiH}_{4}$ plasmas. Moreover, it is important to notice that the growth rate of nanoparticles is about 100 times faster in the case of pure $\mathrm{SiH}_{4}$. Thus, the growth kinetic is an important factor to be considered when 


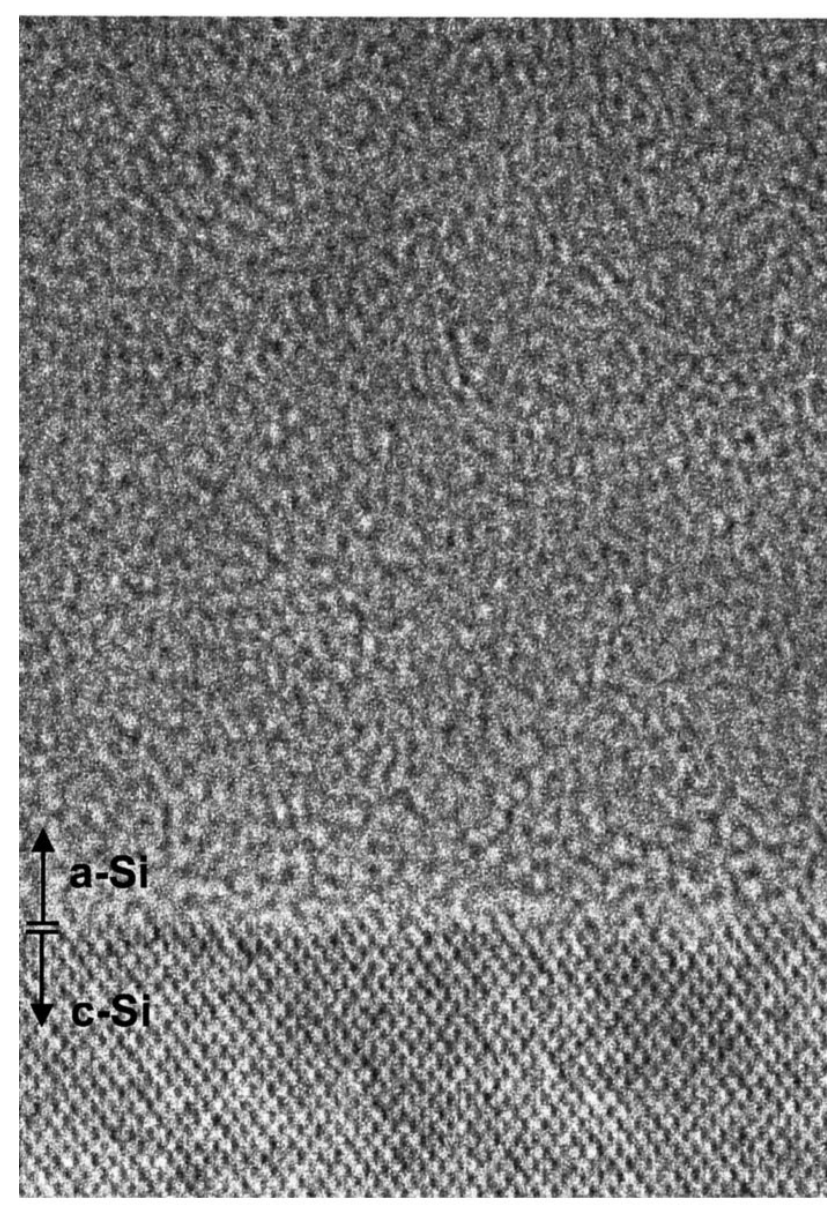

FIG. 5. Cross-section HRTEM image of an amorphous Si thin film deposited on a substrate of crystalline Si.

obtaining silicon crystallites. As a matter of fact, no crystalline particles have been observed in pure $\mathrm{SiH}_{4}$ [4].

The question which remains now is: what atomic structure or structures do the particles have?

\section{B. High-resolution TEM analysis}

HRTEM images are widely used to characterize the atomic structure of small crystalline domains. Nanocrystallite size, shape, surface (crystal/matrix interface) and crystalline lattice can be determined. However, the analysis and identification of nanocrystals of a few nanometers by this method is highly arduous, first because crystallites in the range of 1-2 nm are not easily detected on the images, and second because the crystallites analyzed must be well oriented along the optical axis. In addition, the number of crystalline planes observed in HRTEM images is too small (just 5 planes for a silicon crystallite of 1.5 $\mathrm{nm}$ ) and maybe irregularly distributed due to boundary effects. This, therefore, limits the quantitative information that one can take out by numerical processing of the HRTEM images. Moreover, the nsSi samples analyzed here present a low density of ordered domains (<5\% [19]). This makes the Fourier transform of the images very noisy, since the
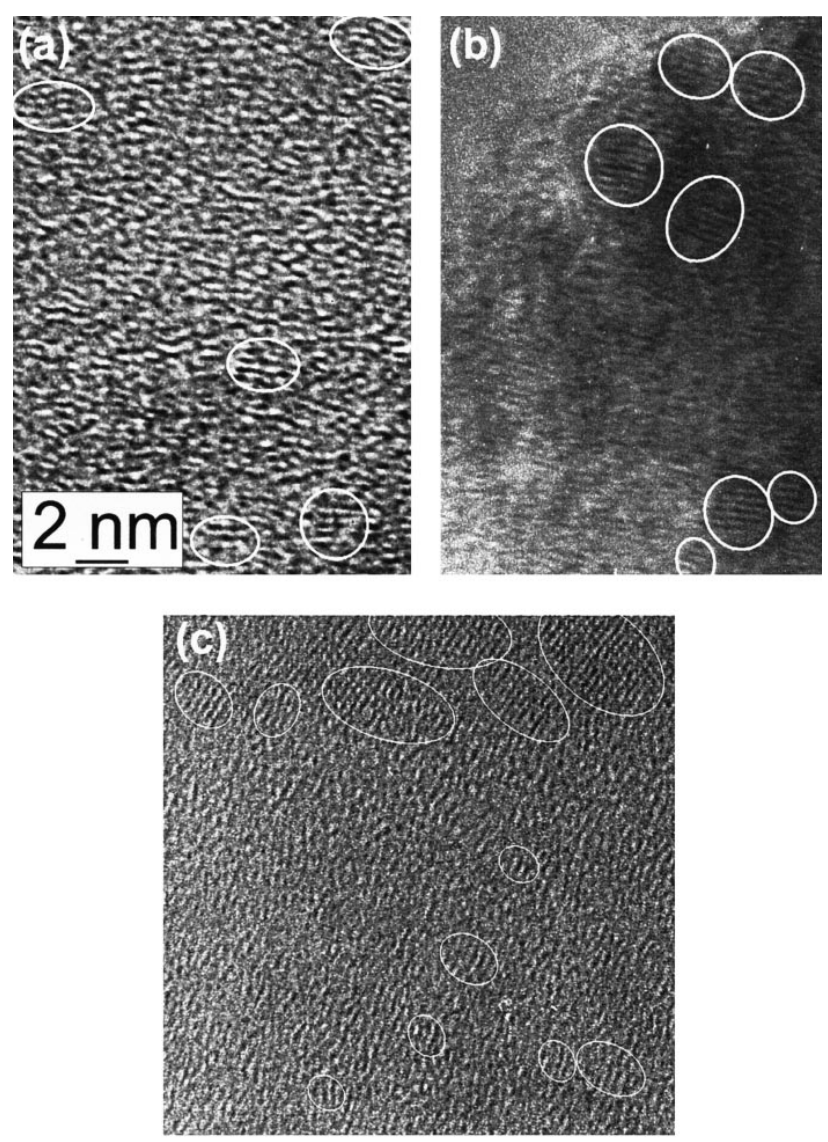

FIG. 6. HRTEM images of the samples (a) ns-Si(A), (b) ns$\mathrm{Si}(\mathrm{B})$, and (c) ns-Si(C). Some of the ordered domains embedded in the amorphous matrix are surrounded by a white line.

amorphous matrix hides the information coming from the nanocrystalline regions. Therefore, we preferred to compare directly the simulated patterns to those observed on the HRTEM images.

Figure 5 shows a HRTEM image of an amorphous Si thin film deposited on a crystalline silicon substrate. The periodic structure being observed on the micrograph corresponds to the $\{111\}$ planes of the $\mathrm{Si}$ diamond structure, crossing each other at $70^{\circ}$. The image is seen along a $<110>$ direction. For the amorphous Si film, the short-range order reaches only the first and second neighbors and therefore, non-periodicity appears on HRTEM image as observed in Fig. 5.

However, for ns-Si films, a medium-range order is expected, associated to Si crystallites of $1-5 \mathrm{~nm}$ embedded in the amorphous matrix. Figure 6 shows HRTEM images of different ns-Si samples. The samples of Figs. 6a and 6b were obtained from cw plasmas of $\mathrm{SiH}_{4}$ highly diluted in $\mathrm{H}_{2}$ under different conditions (ns-Si(A) and ns-Si(B)). In both cases, films were deposited in a regime close to powder formation where $\mathrm{Si}$ nanoparticles of 1-3 $\mathrm{nm}$ can nucleate in the plasma gas phase and contribute to film growth. The ordered domains highlighted in Figs. 6a and $6 \mathrm{~b}$ are assigned to these nanoparticles. Such 


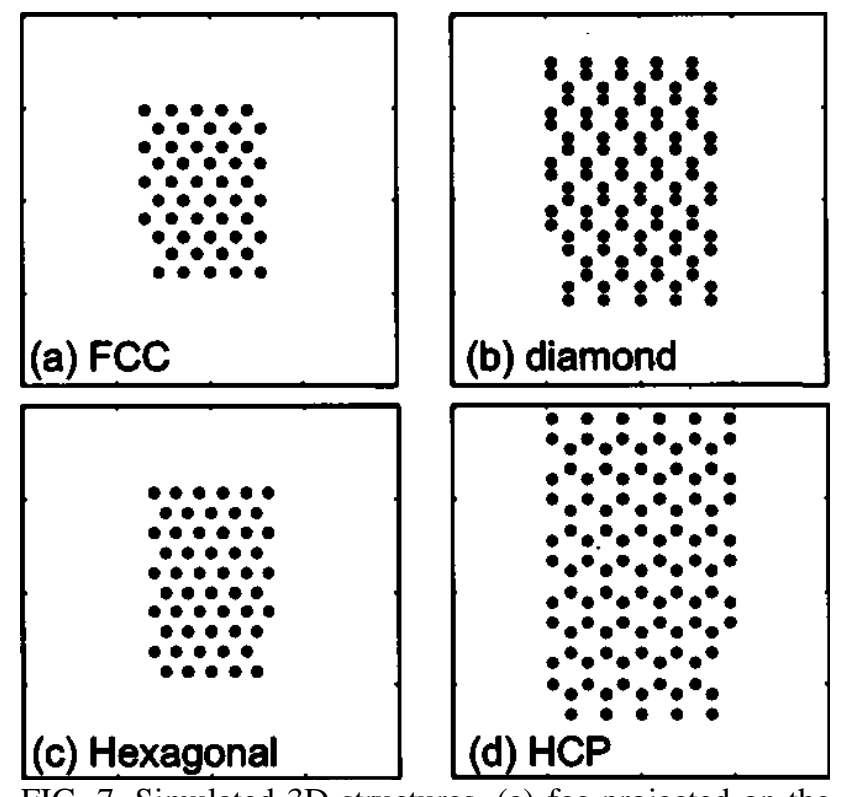

FIG. 7. Simulated 3D structures, (a) fcc projected on the [110] direction with $a=3.9 \AA$, (b) diamond projected on the [110] direction with $a=5.4 \AA$, (c) hexagonal projected on the [001] direction with $a=2.46 \AA$, (d) hcp projected on the [001] direction with $a=3.8 \AA$.

ordered domains were found to be absent in the standard amorphous Si sample. These domains cannot be interpreted as Moiré patterns because the distance between Moiré fringes is much larger than that corresponding to atomic planes. The sample presented in Fig. 6c was obtained in dust-forming plasma conditions and using SQWM to control particle size. The larger ordered domains observed in Fig. 6c correspond to particles formed in the plasma just after the coagulation process, and incorporated onto the films during the afterglow periods $\left(\mathrm{T}_{\text {off }}\right)$.

Most of the ordered domains appearing in the HRTEM images of ns-Si samples are found between 1 and $2 \mathrm{~nm}$. Their images are limited by several planes and only faces in one direction can be observed, thus indicating that they are not well oriented along the optical axis. Therefore, they can not be used to study the atomic structure. The interplanar distance measured directly on the photographs is slightly different for the three samples shown in figure 6: a) $3.5-4 \AA$; b) $3.1-3.5 \AA$; and c) $3.0-3.4 \AA$. These distances correspond to the minimum and maximum values measured in the photographs. These values of interplanar distances will be discussed below from the analysis of the corresponding SAED patterns.

Larger particles can also be observed in Fig. 6c. Some of these ordered domains are well oriented along their principal zone axis, and therefore the families of planes characteristics of the projection are represented in the image. In order to determine the structure, the images of the ordered domains can be compared with simulated crystalline structures projected along their principal axis. Figure 7 presents the calculated fcc and

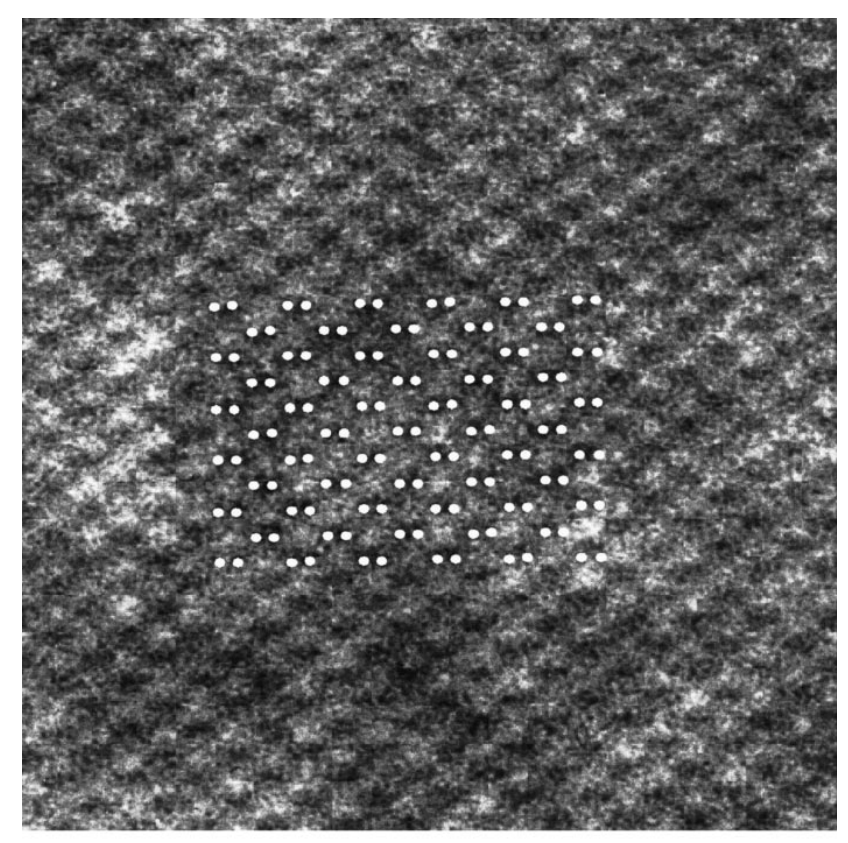

FIG. 8. HRTEM image of $c$-Si (6.12 nm width). The white points represent the simulated diamond structure assuming that each speck corresponds to a couple of atoms.

diamond structures seen along [110], and the hexagonal and hexagonal close-packed (hcp) structures seen along c-axis. Structures were simulated in $3 \mathrm{D}$ taking into account the primitive vectors for each lattice. For the diamond and hcp structures, it was considered that both lattices are formed by two interpenetrating fcc and hexagonal sub-lattices respectively. To assess the lattice calculations, a HRTEM image of $c$-Si seen along [110] (showing planes of the family $\{111\}$ ) has been compared with the simulated diamond lattice (Fig. 8). The simulation is found to reproduce exactly the Si crystalline lattice with a simulated lattice parameter of $5.4 \AA$ and a distance between the $\{111\}$ planes of $3.1 \AA$. These values are in good agreement with the theoretical ones. We can notice in Fig. 8 that each black speck is well described by two atoms of the simulated lattice. This observation explains the elongated shape of the specks. This effect is the consequence of two phenomena. The first one is that the distance between the two atoms of a speck is smaller than the distance between atoms of two different specks, thus the resolution is not sufficient to individualize the atoms in the first case. The second reason is the existence of a blurring effect due to the superimposition of the well-oriented $\{111\}$ planes of the successive atomic layers parallel to the image plane. Indeed, a very small fluctuation in atoms alignment reduces the sharpness of the visible speck.

In the same way, we have simulated the hexagonal close packed structure found in a polymorphous $\mathrm{Si}$ thin film [37]. We can show a good agreement between the hcp simulation projected on the [001] 


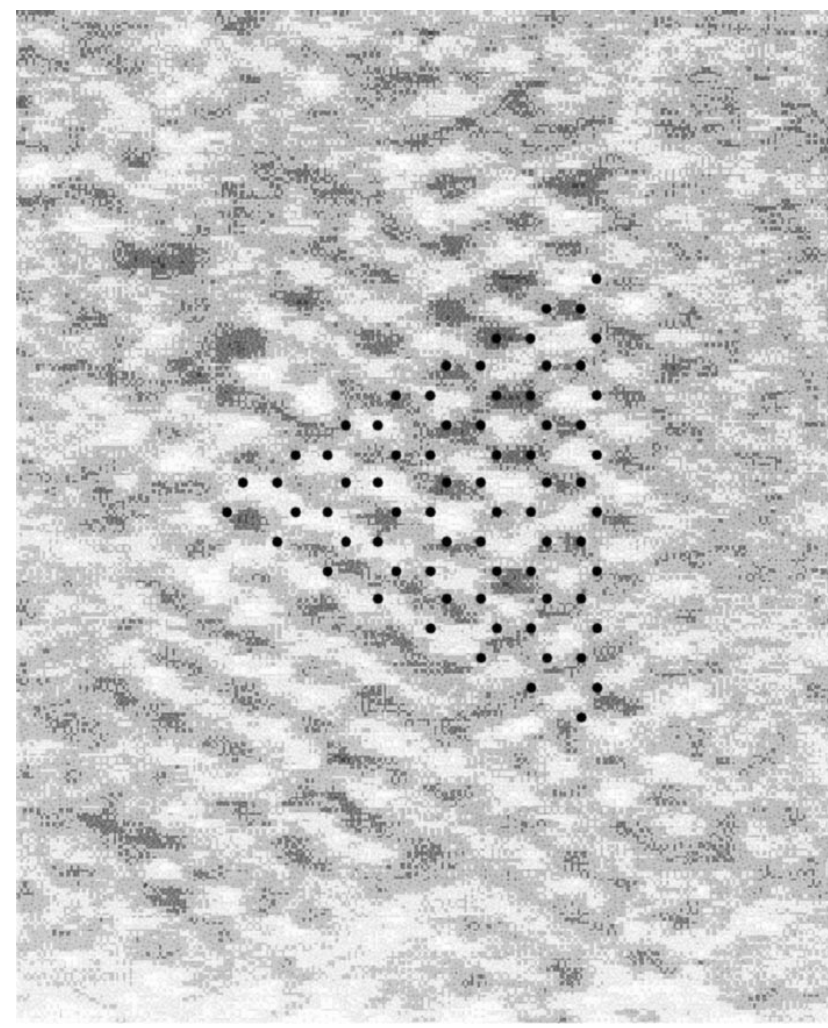

FIG. 9. HRTEM image (5.5 nm width) of a hcp structure for Si (Ref. 37) and the 3D simulated structure projected along the [001] direction with $a=3.8 \AA$.

direction and the HRTEM image taking $a=3.8 \AA$ (Fig. 9). The distance between the $\{100\}$ planes is approximately $3.3 \AA$.

With these results we can try to simulate more unusual structures observed for ns-Si films. Figure 10 shows a HRTEM image of an ordered domain embedded in the ns-Si(C) sample. In these experimental conditions a lot of nanoparticles are obtained with a majority of very small ones showing only a few planes on the HRTEM image. We have not found small particles sufficiently well oriented to allow the simulation of their structure. Therefore we have searched for larger particles on the same sample. The nanoparticle shown in Fig. 10a revealed at least two well-defined families of planes. The simulated lattices for fcc structure along the [100] direction with $a=3.7 \AA$ and for diamond structure along the [110] direction with $a=5.4 \AA$ are reproduced in Figs. 10b and 10c, respectively. The choice of these two theoretical lattices comes from SAED results showing that both structures exist in this sample, as we will discuss in the next part. Figure 10 shows that the diamond structure reproduces the observed planes, much better than the simulated fcc which exhibits intermediate planes.

However, the overlapping of real and simulated structures in Fig. 10 is not so good as in Figs. 8 and 9, and only some hypothesis on the real structure of the deposited nanoparticles can be made from the HRTEM
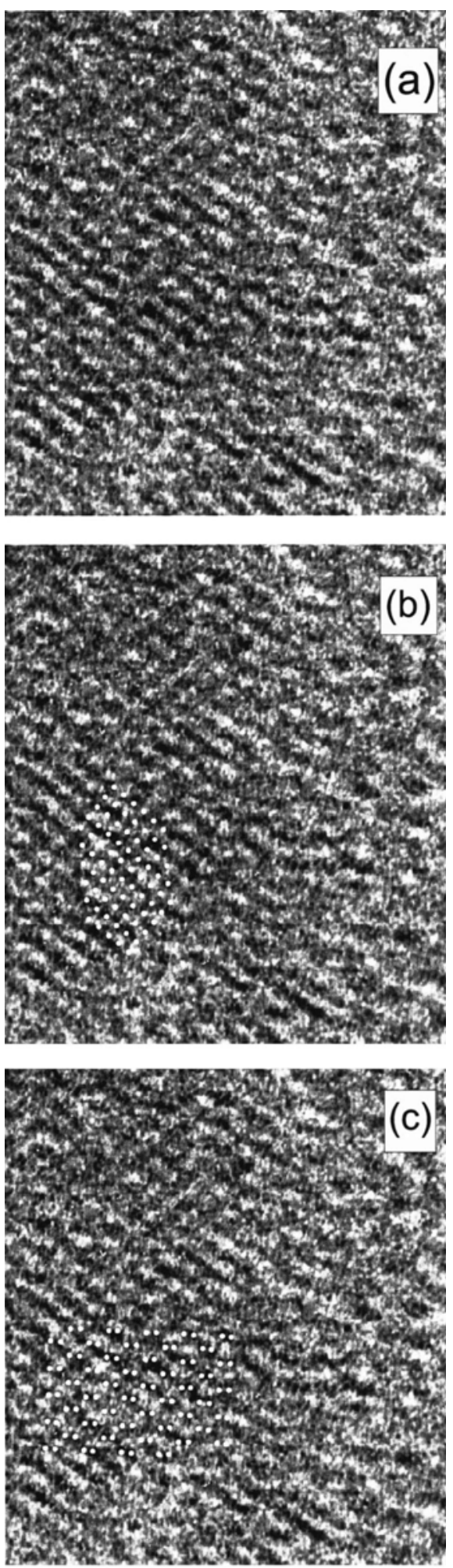

FIG. 10. (a) HRTEM image (6.4 nm width) of a nanocrystallite (left part of the image), superimposition of (b) the simulated fcc structure projected on the [100] plane with $a=3.7 \AA$ and (c) the simulated diamond structure projected on the [110] plane with $a=5.4 \AA$.

analysis. The electron diffraction pattern will show that the fcc and diamond structures coexist in this sample with a more important fcc structure contribution. Subsequently the majority of the nanoparticles must exhibit this structure type and it is 

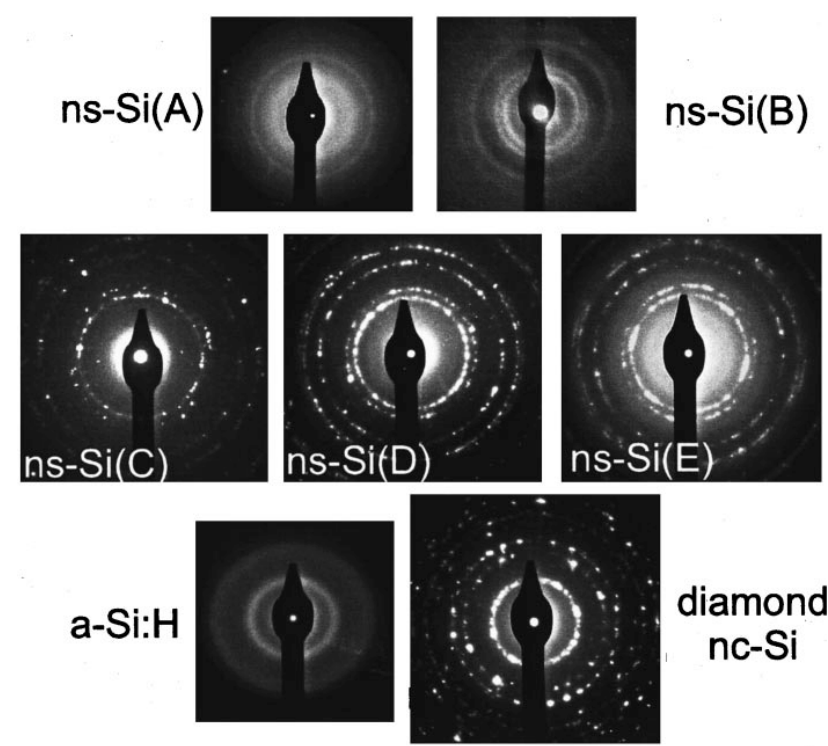

diamond nc-Si

FIG. 11. SAED images of the nanostructured Si samples reported in the experimental section. For comparison, the SAED images of amorphous and nanocrystalline diamondlike silicon are shown in the bottom.

certainly the case of the smallest particles. Nevertheless this structure cannot be confirmed by HRTEM analysis where we need nanoparticles sufficiently large and well oriented. In this case, the simulation has shown that the larger particles have a more stable diamondlike structure. In order to get more information on these two types of structures, the corresponding SAED patterns have been carefully analyzed.

\section{Electron diffraction analysis}

Figure 11 shows the selected area electron diffraction (SAED) patterns of different nanostructured Si thin films and Si nanoparticles obtained using the plasma conditions reported in the experimental section. The SAED patterns of amorphous and nanocrystalline Si with the diamond structure ( $a$-Si:H and nc-Si, respectively) are also given as a reference. The nc-Si sample was obtained by annealing the ns-Si(A) sample at $590^{\circ} \mathrm{C}$ [20]. The thermal annealing process provoked the growth of the Si crystallites already present in the sample and their transformation to the diamondlike structure.

The SAED pattern of the nc-Si sample contains the well-known diffraction rings of the diamond lattice, the most intense corresponding to the planes $\{111\}$, $\{220\}$ and $\{311\}$. For amorphous Si, the distance to first neighbors is the same as in crystalline $\mathrm{Si}$, and therefore, its diffraction diagram is characterized by a first broad ring corresponding to $\{111\}$ planar spacing in diamond $\mathrm{Si}$ and the second one to the combination of $\{220\}$ and $\{311\}$ reflections of the same structure.

The SAED patterns of the as-deposited nanostructured Si samples do not agree with the diamond lattice. In order to identify their atomic structure without ambiguity, we have indexed the diffraction rings on the basis of cubic and hexagonal cells. For cubic cells, the interplanar distance $d_{h k l}$ is related to the lattice constant $a$ through:

$$
\frac{1}{d_{h k l}^{2}}=\frac{h^{2}+k^{2}+l^{2}}{a^{2}}
$$

where $h, k$ and $l$ are the Miller indexes of the lattice planes. For hexagonal structures, an extra variable (c, the vertical stacking distance) is involved. Equation (1) is modified to:

$$
\frac{1}{d_{h k l}^{2}}=\frac{4}{3 a^{2}} \cdot\left(h^{2}+h k+k^{2}\right)+\frac{l^{2}}{c^{2}}
$$

Table II summarizes the results corresponding to the indexation of the SAED images shown in Fig. 11. All the diffraction peaks were well indexed assuming cubic cells. The indexation for hexagonal cells was also tried, but the results did not lead to assert any hexagonal structure.

Most of the SAED patterns of the ns-Si:H samples are in very good agreement with a facecentered-cubic (fcc) structure. Only the SAED pattern corresponding to the ns-Si:H(B) sample could not be indexed according to this lattice. In this case, the indexation revealed a symmetry body-centered like (I), and in particular, the bc8 structure classified by the space group Ia3 (206). The indexation of the SAED patterns of both amorphous and nanocrystalline diamondlike Si are also shown in Table II.

Although it is accepted that the diamond structure is not the most stable structure for small Si crystallites of few number of atoms $(<2 \mathrm{~nm})$ [38], very little information is found in the literature on the particular atomic structure of the nanoparticles created in $\mathrm{rf}$ plasmas [4, 15, 22, 33, 37, 39]. In the literature, the fcc and bc8 phases have not been previously reported for Si nanocrystallites. These phases are generally given as unstable polytypes of Si which can be obtained under high pressures, as will be discussed below.

These results are in good agreement with the measurements deduced from the HRTEM analysis of the smaller crystalline domains in the ns-Si films (Fig. 6 ). The interplanar distances measured directly on the photographs were found to be in the range of 3-4 $\AA$. These distances are too large if they want to be assigned to the $\{111\}$ planes of the diamond structure. However, they can be attributed to the family of $\{100\}$ planes in the fcc structure having a $a=3.65 \AA$ (mean value calculated from the indexation shown in Table II), or, in the case of bc8 structure, to the $\{200\}$ planes having a $d_{h k l}=3.34 \AA$ (Table II).

Of great relevance is that different lattice constants are deduced depending on whether thin films or free- 
TABLE II. Indexation of the SAED patterns shown in figure 11 on the basis of the cubic symmetry. $d_{h k l}$ corresponds to the interplanar distances of the planes $\{\mathrm{h} \mathrm{k} \mathrm{l}\}$ and $a$ the lattice constant calculated from equation 1.

\begin{tabular}{|c|c|c|c|c|c|}
\hline Sample & Ring & $\mathbf{d}_{\mathrm{hkl}}$ & hkl & a $(\AA)$ & Space group \\
\hline \multirow[t]{2}{*}{ a-Si:H } & 1 & 3.06 & 111 & 5.300 & \multirow{2}{*}{ Amorphous } \\
\hline & 2 & 1.76 & $\begin{array}{l}220 \\
311\end{array}$ & - & \\
\hline \multirow[t]{7}{*}{ nc-Si } & 1 & 3.13 & 111 & 5.421 & \multirow{7}{*}{$\begin{array}{l}\text { Cubic Diamond } \\
\text { Fd3m (227) }\end{array}$} \\
\hline & 2 & 1.91 & 220 & 5.401 & \\
\hline & 3 & 1.65 & 311 & 5.468 & \\
\hline & 4 & 1.37 & 400 & 5.474 & \\
\hline & 5 & 1.27 & 331 & 5.539 & \\
\hline & 6 & 1.11 & 422 & 5.429 & \\
\hline & 7 & 1.05 & 511 & 5.454 & \\
\hline \multirow[t]{5}{*}{ ns-Si:H(A) } & $\overline{1} 1$ & 2.11 & 111 & 3.659 & \multirow{5}{*}{$\begin{array}{c}\text { Cubic fcc } \\
\text { Fm3m (225) }\end{array}$} \\
\hline & 2 & 1.82 & 200 & 3.634 & \\
\hline & 3 & 1.30 & 220 & 3.677 & \\
\hline & 4 & 1.10 & 311 & 3.663 & \\
\hline & 5 & 0.84 & 331 & 3.665 & \\
\hline \multirow[t]{5}{*}{ ns-Si:H(B) } & 1 & 3.34 & 200 & 6.680 & \multirow{5}{*}{$\begin{array}{c}\text { Cubic bc8 } \\
\text { Ia3 (206) }\end{array}$} \\
\hline & 2 & 2.65 & 211 & 6.499 & \\
\hline & 3 & 1.77 & 321 & 6.614 & \\
\hline & 4 & 1.44 & 420 & 6.432 & \\
\hline & 5 & 1.13 & 440 & 6.373 & \\
\hline \multirow[t]{7}{*}{ ns-Si:H(C) } & 1 & 2.11 & 111 & 3.659 & \multirow{7}{*}{$\begin{array}{c}\text { Cubic fcc } \\
\text { Fm3m (225) }\end{array}$} \\
\hline & 2 & 1.83 & 200 & 3.654 & \\
\hline & 3 & 1.29 & 220 & 3.649 & \\
\hline & 4 & 1.10 & 311 & 3.640 & \\
\hline & 5 & 1.05 & 222 & 3.625 & \\
\hline & 6 & 0.84 & 331 & 3.647 & \\
\hline & 7 & 0.81 & 420 & 3.616 & \\
\hline \multirow[t]{7}{*}{ ns-Si:H(D) } & $\overline{c 1}$ & 2.36 & 111 & 4.083 & \multirow{7}{*}{$\begin{array}{c}\text { Cubic fcc } \\
\text { Fm3m (225) }\end{array}$} \\
\hline & 2 & 2.03 & 200 & 4.058 & \\
\hline & 3 & 1.44 & 220 & 4.065 & \\
\hline & 4 & 1.22 & 311 & 4.053 & \\
\hline & 5 & 1.18 & 222 & 4.085 & \\
\hline & 6 & 0.94 & 331 & 4.093 & \\
\hline & 7 & 0.91 & 420 & 4.048 & \\
\hline \multirow[t]{6}{*}{ ns-Si:H(E) } & 1 & 2.37 & 111 & 4.108 & \multirow{6}{*}{$\begin{array}{c}\text { Cubic fcc } \\
\text { Fm3m (225) }\end{array}$} \\
\hline & 2 & 2.01 & 200 & 4.024 & \\
\hline & 3 & 1.44 & 220 & 4.068 & \\
\hline & 4 & 1.23 & 311 & 4.076 & \\
\hline & 5 & 1.17 & 222 & 4.037 & \\
\hline & 6 & 0.91 & 420 & 4.085 & \\
\hline
\end{tabular}

standing nanoparticles are analysed. For the dense nanostructured thin films with the fcc structure, the lattice constant deduced from the indexation is found to be around $3.65 \AA$, while that for both samples of $\mathrm{Si}$ nanoparticles, the lattice constant is around $4.05 \AA$. Note that the error in both cases is very small (about $1 \%)$, thus validating the crystalline indexation. Different reasons can explain such difference in constant lattice:

(a) The particle/matrix interfacial energy: for nanostructured thin films, the crystallites are embedded in an amorphous matrix, while for the sample of Si nanoparticles they are isolated on a TEM grid. The interfacial energy is therefore smaller for the nanoparticles and this may explain their expanded lattice.

(b) The crystallite size: the mean size of the $\mathrm{Si}$ crystallites embedded in the nanostructured films is around $2 \mathrm{~nm}$, while the diameter of the $\mathrm{Si}$ nanoparticles is around $10 \mathrm{~nm}$. The surface energy is therefore smaller for the nanoparticles and this is also in agreement with their expanded lattice. 


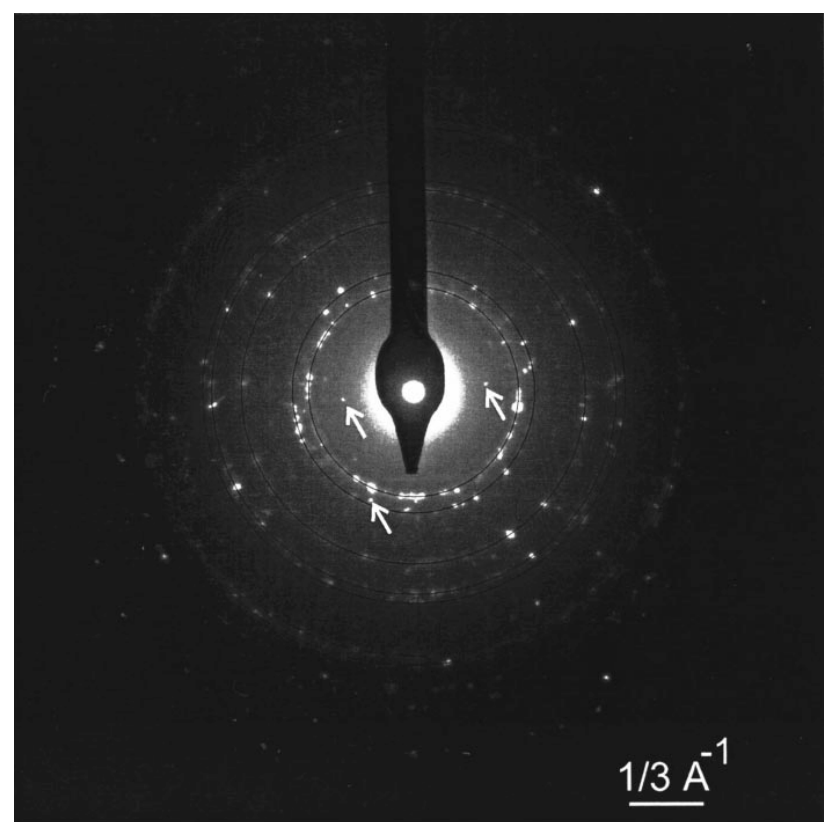

FIG. 12. Detailed analysis of the SAED image of the ns$\mathrm{Si}(\mathrm{C})$ sample. The diffraction rings of the fcc structure are highlighted by black circumferences. The white arrows point out diffraction spots coming from the diamond symmetry.

Another remarkable aspect is that, in spite of the very different plasma conditions used to deposit ns$\mathrm{Si}(\mathrm{A})$ and $\mathrm{ns}-\mathrm{Si}(\mathrm{C})$, their crystalline structure is found to be the same. The ns-Si(A) sample was obtained in rf plasmas of $\mathrm{SiH}_{4}$ diluted in $\mathrm{H}_{2}$ under conditions of low particle development in the plasma. Note that the corresponding SAED image contains both distinct and diffuse rings, thus revealing a low density of crystallites. However, the ns-Si(C) sample was obtained in dust-forming plasmas of $\mathrm{SiH}_{4}$ diluted in $\mathrm{Ar}$, and the incorporation of particles onto the film was controlled through the modulation of the plasma. The crystalline density of the ns- $\mathrm{Si}(\mathrm{C})$ sample is higher, as clearly seen from its SAED containing only well defined rings. Nevertheless, in both cases the crystalline entities are known to come from particles formed in the plasma gas-phase and therefore, it is reasonable they have a similar crystalline structure.

However, the existence of different crystalline lattices in the nanostructured Si thin films, as the fcc and bc8 phases deduced from the SAED images of Fig. 11, is hard to explain. Other authors have also identified a lonsdaleite phase (hcp) [37], in agreement with the modelization of the corresponding HRTEM image presented here. In addition, crystallites of $\mathrm{Si}$ with the hcp structure have been obtained by clusterbeam evaporation [40] and by laser ablation [41]. In the laser ablation technique, particles are also formed under extreme non-equilibrium conditions and this allows the formation of metastable Si structures to be stable in the nanometer scale. The existence of stable phases for nanostructured $\mathrm{Si}$ that are usually metastable or unstable for macroscopic bulk silicon is commonly related to size effects. For particles of a few nanometers the surface effect may play a predominant role [42]. The bonding configuration of atoms on the surface of nanocrystals is maybe distinct from that of the bulk to reduce the Gibbs free energy.

Other factors related to the process of particle formation by rf plasma, such as the process temperature, pressure and the inert gas dilution, may play an important role in the reconstruction of the particle structure. In early stages of nanocrystal formation, metastable structures may be favored by the kinetics of development. In Sec. 3A, we have shown that the Ar dilution induces the crystallization of the $\mathrm{Si}$ nanoparticles. The surface reconstruction of the particles upon ion bombardment may favor the formation of metastable structures that can minimize the total energy, giving place to an uncommon stable Si phase. In addition, ns-Si films are highly hydrogenated [21,31] and the saturation of the crystallite surface with hydrogen can also influence the most stable structure.

Figure 12 shows in more detail the SAED image of the ns-Si(C) sample. In the figure, dashed circumferences have been superimposed to the diffraction rings used to index the structure. The radius of each circumference corresponds exactly to the value used to calculate the corresponding interplanar distances $d_{h k l}$ which appear in Table II. A careful inspection of the figure reveals the presence of weak diffraction spots at about $3.1 \AA$ and $1.9 \AA$, which agree with the $\{111\}$ and $\{220\}$ planes of the diamond lattice.

The density of diamond crystallites is smaller than the density of fcc crystallites, as seen by the low intensity of their diffraction spots. In addition, diamond crystallites produce well defined points while the fcc ones give dotted rings, thus revealing that the diamondlike diffractions stem from larger particles. These results indicate that the ns-Si(C) sample is mainly constituted by fcc crystallites but some larger diamondlike Si crystals are also embedded in the matrix. This agrees with the HRTEM results shown in the last sections, where the larger crystallites found in the photographs were well simulated using the diamond lattice. The smaller crystalline entities (with size around $2 \mathrm{~nm}$ ), identified here as fcc or bc8 crystallites, are too small to be studied directly from the HRTEM images.

The fcc, bc8 and hcp phases have been reported as possible high-pressure phases of Si [43, 44]. Numerous high-pressure experiments have been performed, revealing not less than 12 different polymorphs of silicon until now. For example, the bc8 phase can be obtained at ambient pressure after compressing the diamond structure to form the 
metallic $\beta$-Sn phase and then unloading [45]. A compilation of experimental results for compressed $\mathrm{Si}$ has been done by $\mathrm{Hu}$ et al. [43] and theoretical calculations are summarized by Chang and Cohen [44]. From the calculations of the total energies $\left(E_{T}\right)$ of all the different phases, the diamond structure appears as the most stable phase.

Of very important relevance is the high similarity that exists between the bc8, hcp and fcc phases. Besides their nearly identical packing fraction $(0.34$, 0.68, 0.74 and 0.74 for the diamond, bc8, hcp and fcc, respectively), coordination number (4, 8, 12 and 12), and relative nearest-neighbor (1, 1.260, 1.296 and 1.296), the three phases present a very similar total structural energy. When compared to the energy of the diamond structure, the difference of structural energy between the three phases is smaller than $10 \%[44,46]$. The formation of anyone of these structures under particular conditions of crystal nucleation should not then be privileged with respect to the others. Therefore, it is reasonable that we have observed the formation of Si crystallites with bc8 and fcc, while other authors had obtained samples grown by the same technique but with the hcp structure [37].

\section{CONCLUSIONS}

Low-temperature $\left(\mathrm{RT}-250^{\circ} \mathrm{C}\right) \quad \mathrm{SiH}_{4}$-based rf plasmas have been used to produce silicon thin films consisting of a two-phase mixture of amorphous and ordered Si. These films, referred to as polymorphous or nanostructured $\mathrm{Si}$, are obtained under a wide variety of plasma conditions, but always allowing the formation of crystalline Si nanoparticles in the plasma gas phase and their contribution to the film deposition. The role of the dilution of $\mathrm{SiH}_{4}$ in an inert gas $\left(\mathrm{Ar}, \mathrm{H}_{2}\right)$ on the particle crystallinity has been emphasized. These particles maintain the same atomic structure once incorporated into the film, thus leading to the particular crystalline structure of the polymorphous films as observed by electron diffraction.

HRTEM analysis has evidenced the presence of ordered domains embedded in an amorphous $\mathrm{Si}$ matrix. From the modelization of different crystalline structures, a detailed analysis of the HRTEM images has been performed. However, unambiguously structural information cannot be obtained due to the small size of the nanocrystalline domains.

The atomic structure of the films has been well resolved by using the SAED technique. SAED images of polymorphous $\mathrm{Si}$ thin films and of isolated $\mathrm{Si}$ nanoparticles have revealed the existence of different cubic phases: fcc and bc8. These phases are commonly unstable under ambient conditions and can be obtained under pressure compression. The occurrence of such phases in low-temperature plasma processes has been explained in terms of the particular kinetics of development of the particles in the plasma, and of the stability changes involving size effects. The fcc and bc8 phases are very similar to the hexagonal hcp one, which is currently reported in the literature for nanocrystalline $\mathrm{Si}$.

\section{ACKNOWLEDGMENTS}

This study was financed by the European Community under contract "H-Alpha Solar” N. ERK6CT-1999-00004 and partially supported by CICYT, MAT99-0569-CO2-01 of the government of Spain. The authors want to express their gratitude to Juan Carlos Ferrer (from the Serveis Cientifico-Tecnics of the University of Barcelona) for their collaboration with the TEM measurements, Stephanie Huet for the preparation of the ns-Si(C) sample, Dr. Josep Costa for the SAED image of the ns-Si(D) sample, Ana Fontcuberta i Morral for the HRTEM image of figure 9 and Dr. Alain Pineau for helpful discussions on the electron diffraction patterns.

[1] N. Hershkowitz, Plasma Sources Sci. Technol. 3, 239 (1994)

[2] R.N Carlile, J. Vac. Sci. Technol. A 14, 487 (1996)

[3] Dusty Plasmas, Physics, Chemistry and Technological Impacts in plasma processing, ed. A. Bouchoule (Wiley, New York, 1999)

[4] J. Costa, Nanoparticles from low-pressure lowtemperature plasmas, in Handbook of Nanostructured Materials Vol. 1, ed. Hari Singh Nalva (Academic Press, New York, 2000)

[5] J.T. Verdeyen, J. Beberman, L. Overzet, J. Vac. Sci. Technol. A 81851 (1990)

[6] A.A. Howling, L. Sansonnens, J.-L. Dorier, Ch. Hollenstein, J. Appl. Phys. 75, 1340 (1994)

[7] A. Garscadden, B.N. Ganguly, P. D. Haaland, J. Williams, Plasma Sources Sci. Technol. 3, 239 (1994)

[8] L. Boufendi, A. Plain, J. Ph. Blondeau, A. Bouchoule, C. Laure, M. Toogood, Appl. Phys. Lett. 60, 169 (1992)

[9] L. Boufendi and A. Bouchoule, Plasma Sources Sci. Technol. 3, 262 (1994).

[10] L. Boufendi, J. Herman, A. Bouchoule, B. Dubreuil, E. Stoffels, W.W Stoffels, M.L. deGiorgi, J. Appl. Phys. 76, 148 (1994).

[11] Y. Watanabe, M. Shiratani, H. Makino, Appl. Phys. Lett. 57, 1616 (1990)

[12] A. Lloret, E. Bertran, J.L. Andújar, A. Canillas, J.L. Morenza, J. Appl. Phys. 69, 632 (1991)

[13] J.L. Andújar, E. Bertran, A. Canillas, J. Campmany, J. Serra, C. Roch, J. Appl. Phys. 71, 1546 (1992)

[14] C. Longeaud, J. P. Kleider, P. Roca i Cabarrocas, S. Hamma, R. Meaudre, M. Meaudre, J. Non-Cryst. Solids 227-230, 96 (1998)

[15] P. Roca i Cabarrocas, Mater. Res. Soc. Symp. Proc. 507, 855 (1998)

[16] P. Roca i Cabarrocas, J. Non-Cryst. Solids 266-269, 31 (2000) 
[17] M. Meaudre, R. Meaudre, R. Butté, S. Vignoli, C. Longeaud, J. P. Kleider, P. Roca i Cabarrocas, J. Appl. Phys. 86, 946 (1999)

[18] P. Roca i Cabarrocas, P. Gay, A. Hadjadj, J. Vac. Sci. Technol. A 14, 655 (1996)

[19] G. Viera, S. Huet, E. Bertran and L. Boufendi, J. Appl. Phys. 90, 4272 (2001)

[20] E. Bertran, S. N. Sharma, G. Viera, J. Costa, P. St'ahel and P. Roca i Cabarrocas, J. Mater. Res. 13, 2476 (1998)

[21] G. Viera, P. Roca i Cabarrocas, J. Costa, S. Martinez, E. Bertran, Mater. Res. Soc. Symp. Proc. 507, 933 (1998)

[22] J. Costa, P. Roura, P. Roca i Cabarrocas, G. Viera, E. Bertran, Mater. Res. Soc. Symp. Proc. 507, 499 (1998)

[23] S. Veprek, Z. Iqbal, F.-A. Sarott, Phil. Mag. B 45, 137 (1982)

[24] J.R. Chelikowsky, J.C. Phillips, Phys. Rev. Lett. 63, 1653 (1989)

[25] M.V. Ramakrishna, J. Pan, J. Chem. Phys. 101, 8108 (1994)

[26] J. Pan, M.V. Ramakrishna, Phys. Rev. B 50, 15431 (1994)

[27] U.R. Röthlisberger, W. Andreoni, M. Parinello, Phys. Rev. Lett. 52, 665 (1994)

[28] H. Hofmeister, J. Dutta, H. Hofmann, Phys. Rev. B 54, 2856 (1996)

[29] G.K. Ramachandran, J. Diefenbacher, O.F. Sankey, R. Sharma, R.F. Marzke, M. O’Keeffe, J. Gryko, P.F. McMillan, Mater. Res. Soc. Symp. Proc. 507, 483 (1998)

[30] P. Roca i Cabarrocas, J.B. Chévrier, J. Huc, A. Lloret, J.Y. Parey, and J.P.M. Schmitt, J. Vac. Sci. Technol. A 9, 2331 (1991).

[31] P. Roca i Cabarrocas, S. Hamma, S.N. Sharma, G. Viera, E. Bertran, J. Costa, J. Non-Cryst. Solids 227-230, 871 (1998)

[32] A. Bouchoule, A. Plain, L. Boufendi, J. Ph. Blondeau, and C. Laure, J. Appl. Phys. 70, 1991 (1991).

[33] G. Viera, E. García-Caurel, J. Costa, J.L. Andújar, E. Bertran, Appl. Surf. Sci. 144, 702 (1999)

[34] See for example: L. Boufendi, A. Bouchoule, T. Hbid, J. Vac. Sci. Technol. A 14, 572, (1996); A. Fridman, L. Boufendi, T. Hbid, B. Potapkin and A. Bouchoule, J. Appl. Phys. 79, 1303 (1996); S. J. Choi and M. J. Kushner, J. Appl. Phys. 74, 853 (1993).

[35] A.A. Howling, L. Sansonnens, J.-L. Dorier, Ch. Hollenstein, J. Appl. Phys. 75, 1340 (1994)

[36] A.A. Howling, C. Courteille, J.L. Dorier, L. Sansonnens, Ch. Hollenstein, Pure Appl. Chem. 68, 1017 (1996)

[37] A. Fontcuberta i Morral, J. Bertomeu, P. Roca i Cabarrocas, J. Non-Cryst. Solids. 266-269, 48 (2000)

[38] J.R. Chelikowsky, J.C. Phillips, Phys. Rev. Lett. 63, 1653 (1989)

[39] H. Hofmeister, J. Dutta, H. Hofmann, Phys. Rev. B 54, 2856 (1996)

[40] J.Y. Zhang, H. Ono, K. Uchida, S. Nozaki and H. Morisaki, Phys. Status Solidi B 223, 41 (2001)

[41] Y. Zhang, Z. Iqbal, S. Vijayalakshmi, H. Grebel, Appl. Phys. Lett. 75, 2758 (1999)

[42] S. H. Tolbert, A.B. Herhold, L. E. Brus, and A. P. Alivisatos, Phys. Rev. Lett. 76, 4384 (1996)

[43] J. Z. Hu, L.D. Merkle, C.S. Menoni, I.L. Spain, Phys. Rev. B 34, 4679 (1986)
[44] K. J. Chang and M. L. Cohen, Phys. Rev. B 31, 7819 (1985)

[45] B.G. Pfrommer, M.Côté, S.G. Louie and M.L. Cohen, Phys. Rev. B 56, 6662 (1997)

[46] M. T. Yin and M. L. Cohen, Phys. Rev. B 26, 5668 (1982) 